\title{
Solithromycin: A New Ketolide Antibacterial Agent in Clinical Trials
}

\section{Bela Kocsis ${ }^{\star}$ and Dora Szabo}

Institute of Medical Microbiology, Semmelweis University, Budapest, Hungary

\section{Abstract}

Solithromycin is a novel agent of macrolide antimicrobial classes that demonstrates treatment option in community-acquired pneumonia (CAP). It showed bactericidal effect against major respiratory tract pathogens namely, Streptococcus pneumonia, Staphylococcus aureus and Haemophilus influenza even against strains exhibiting resistance to commonly used antibiotics. Solithromycin demonstrates broadspectrum antibacterial activity together with other features like intracellular accumulation and antiinflammatory effect. It showed moderately severe adverse events during clinical trails and demonstrated favourable tissue penetration and pharmacokinetic properties. Solithromycin showed non-inferiority to moxifloxacin in clinical trial indicating its possible treatment option in CAP and other lower respiratory tract infections in the future. This commentary describes recent advances regarding solithromycin that has been introduced into clinical trials.

Solithromycin (CEM-101) is a fourth-generation macrolide and belongs to fluoro ketolide agents. It demonstrated bactericide activity during in vitro and in vivo studies against major respiratory tract bacterial pathogens including macrolide and penicillin resistant Streptococcus pneumonia $[1,2]$.

Solithromycin compared to other macrolides (e.g. clarithromycin), lacks L-cladinose in position C3 of the erythronolide ring that leads to a hydroxyl group oxidized to a keto group. This modification enhances acid stability and antimicrobial potency against macrolide-resistant isolates too [3-6]. Solithromycin differs from telithromycin due to a fluorine at position $\mathrm{C} 2$. When bound to the ribosome, this fluorine appears in close to the glycosidic bond (N-1) of C2611 of 23SrRNA, contributing to drug binding on the target and enhancing the agent's antibacterial activity. Thus, solithromycin is capable to bind to three different sites on the ribosome, by contrast, telithromycin binds only to two sites. This feature improves the activity of solithromycin in growth inhibition of Streptococci carrying the erm methyltransferase compared with macrolides lacking the $\mathrm{C} 2$ fluorine, indicating solithromycin's activity against macrolide-resistant isolates too $[1,5,7]$. Chemical structure characteristics of solithromycin include lack of pyridine moiety in its side chain that has been shown to be associated with nicotinic acetylcholine receptor inhibition, which is potentially the cause of certain adverse events (e.g. blurry vision, exacerbation of myasthenia gravis, and hepatotoxicity) $[8,9]$. The main antibacterial effect of solithromycin is the inhibition of $50 \mathrm{~S}$ ribosomal unit formation thus it inhibits bacterial protein synthesis $[5,10]$. This antibacterial activity was detected in vitro $S$. pneumoniae, methicillin-susceptible and methicillin-resistant Staphylococcus aureus and Haemophilus influenzae [11]. Solithromycin achieves remarkable intracellular accumulation compared to currently available macrolides [12], this contributes to treat lower respiratory tract infections (LRTIs) of both extra- and intracellular pathogens [13]. Solithromycin demonstrates anti-inflammatory effect that can also be beneficial during treatment of LRTIs $[14,15]$.

Pharmacokinetic investigations in human individuals during intravenous administration demonstrate approximately $67 \%$ bioavailability following orally administered solithromycin [1]. Food consumption did not interfere the bioavailability of solithromycin as peak plasma concentration $\left(\mathrm{C}_{\max }\right)$, time to reach maximum plasma concentration $\left(\mathrm{T}_{\max }\right)$, and area under the concentration time curve (AUC) following a single 400-mg dose in fasted (for at least10 h) and fed (following a high-fat meal) conditions stayed at similar level [16]. A 542 L distribution volume of solithromycin was achieved during a multiple-dose regimen of $800 \mathrm{mg}$ followed by $400 \mathrm{mg}$ daily for 4 days in healthy adults [17]. A high plasma protein binding (81\%) features solithromycin [13]. The major metabolic pathway of solithromycin is through cytochrome P450, 3A4, with the most metabolites are involved in biliary excretion [17]. In a single-dose escalation study, half-life of solithromycin increased from $3 \mathrm{~h}$ with doses of $100 \mathrm{mg}$ to $7 \mathrm{~h}$ with doses of $1600 \mathrm{mg}$. Generally, there were nonlinear increases in $\mathrm{C}_{\max }$ and $\mathrm{AUC} 0-\infty$ and a prolongation of $\mathrm{T}_{\max }$ from 1.5 to $6 \mathrm{~h}$ over the range of doses [16]. In tissue distribution, solithromycin showed significant accumulation in alveolar macrophages compared with plasma, with a mean macrophage to plasma concentration ratio of 245 (range 44-515) [13].

Altogether two Phase II and two Phase III clinical trials have been conducted with solithromycin. A Phase II trial has evaluated safety and efficacy of solithromycin treatment in community-acquired bacterial pneumonia (Clinical Trials.gov registration number: NCT01168713). Another Phase II clinical trial was investigating solithromycin treatment in urogenital gonorrhea infection (Clinical Trials.gov registration number: NCT01591447).

A Phase III clinical trial demonstrated antibacterial efficacy and safety of oral solithromycin ( $800 \mathrm{mg}$ on day 1 followed by $400 \mathrm{mg}$ daily on days $2-5$ and then placebo daily on days 6-7) versus oral moxifloxacin (400 mg daily for 7 days) for the treatment of community-acquired bacterial pneumonia in a global, double-blind, double-dummy, randomized, active-controlled, non-inferiority trial (SOLITAIREORAL) (ClinicalTrails.gov registration number: NCT01756339). During this study, a total of 860 patients were randomly assigned, with 426 receiving solithromycin and 434 receiving moxifloxacin. Baseline pathogens were identified from blood, respiratory samples whereas $\mathrm{S}$. pneumoniae (23\% of total patients), H. influenzae (16\%), and causative agents of a typical pneumonia (24\%). Successful baseline pathogen identification was in $55 \%$ of patients receiving solithromycin and in $52 \%$ of patients receiving moxifloxacin. The primary outcome was early clinical response, as defined by improvement in at least two of "Corresponding Author: Dr. Bela Kocsis, Institute of Medical Microbiology, Semmelweis University, Budapest, Üllöi út 26, 1085, Hungary; E-mail: kocsis.bela@med.semmelweis-univ.hu

Citation: Kocsis B, Szabo D (2018) Solithromycin: A New Ketolide Antibacteria Agent in Clinical Trials. Int J Clin Med Microbiol 2: 130. doi: https://doi. org/10.15344/2456-4028/2018/130

Copyright: (c) 2018 Kocsis et al. This is an open-access article distributed under the terms of the Creative Commons Attribution License, which permits unrestricted use, distribution, and reproduction in any medium, provided the original author and source are credited. 
four symptoms (cough, chest pain, sputum production, and dyspnea) with no worsening in any symptom at $72 \mathrm{~h}$ after the first dose. Solithromycin was noninferior to moxifloxacin, with early clinical response in $78.2 \%$ versus $77.9 \%$ of patients receiving moxifloxacin (95\% confidence interval [CI], 5.5 to 6.1 ). Treatment failure at short-term follow-up, which occurred 5-10 days following the end of treatment, occurred in $12 \%$ of patients receiving solithromycin and $9 \%$ of patients receiving moxifloxacin. This included lack of resolution, worsening of baseline or development of new symptoms, and the need for new antibacterial treatment [18].

In another Phase III trial (ClinincalTrials.gov registration number: NCT01968733) SOLITAIRE-IV, the efficacy and safety of intravenous-to-oral solithromycin were assessed against intravenousto-oral moxifloxacin for the treatment of community-acquired bacterial pneumonia. In this randomized, global, double-blind, active-controlled, non-inferiority trial, all patients began treatment with $400 \mathrm{mg}$ intravenous solithromycin or moxifloxacin, with a switch to the oral form of the medication $(800 \mathrm{mg}$ and then $400 \mathrm{mg}$ daily for solithromycin; $400 \mathrm{mg}$ daily for moxifloxacin) when clinically indicated for a total treatment duration of 7 days. The criteria for switching to oral therapy were improved signs and symptoms versus baseline, with patients being afebrile with a respiratory rate $\leq 24$ breath per minute, systolic blood pressure $\geq 90 \mathrm{mmHg}$, and $\mathrm{O}_{2}$ saturation $\geq$ $90 \%$ on room air. Patients had to have experience an acute onset or worsening of three of four cardinal symptoms such as cough, dyspnea, chest pain, or purulent sputum production - plus one of the following: fever, hypothermia, and/or pulmonary consolidation. S. pneumoniae was the most common pathogen, accounting for more than $45 \%$ of baseline pathogens, followed by Mycoplasma pneumoniae over 19\% with $H$. influenzae, Legionella spp., and S. aureus each accounting for $\geq 10 \%$. The primary end point was early clinical response (defined by improvement at $72 \mathrm{~h}$ after the first dose in at least two of the four cardinal symptoms, with no other antimicrobial agents received) Solithromycin demonstrated non-inferiority to moxifloxacin $(79.3 \%$ of patients who received solithromycin showed earlyclinical response versus $79.7 \%$ of patients who received moxifloxacin [95\% CI -6.1 to 5.2]). In both treatment arms, there was a median of 3-day duration of intravenous treatment and 4 days of oral treatment [19].

Adverse events of solithromycin were tested during Phase II and Phase III clinical trials, and solithromycin was well tolerated as usually mild adverse events appeared. The most frequent events were nausea, vomiting, diarrhea, transaminase elevation, headache, dizziness, insomnia, hypokalemia, hyponatremia, urticaria, and bilirubin elevation. During intravenous administration, a phlebitis, erythema, paresthesia, and thrombosis appeared. On the 4th of November 2016, the FDA has released a document regarding hepatotoxic adverse events during clinical trials of solithromycin. The rates of liver enzymes (alanine aminotransferase [ALT] and aspartate aminotransferase) were higher in solithromycin-treated patients than those of treated with moxifloxacin. These transaminase elevations remained asymptomatic without bilirubin elevation; however, the severe adverse events that occurred with telithromycin(e.g. hepatotoxicity) have not been detected. It has been also assumed that hepatotoxicity due to solithromycin therapy has not yet been adequately characterized (FDA) [4].

\section{Competing Interests}

The authors declare that there is no competing interest.

\section{Acknowledgement}

Our research team in financially supported by OTKA Hungarian Research Fund: Grant number: 108481.

\section{References}

1. Van Bambeke F, Tulkens PM (2013) The role of solithromycin in the management of bacterial community-acquired pneumonia. Expert Rev Anti Infect Ther 14: 311-324

2. Farrell DJ, Flamm RK, Sader HS, Jones RN (2016) Results from the Solithromycin International Surveillance Program (2014) Antimicrob Agents Chemother 60: 3662-3668.

3. Zhanel GG, Walters M, Noreddin A, Vercaigne LM, Wierzbowski A, et al (2002) The ketolides: a critical review. Drugs 62: 1771-1804.

4. Zhanel GG, Hartel E, Adam H, Zelenitsky S, Zhanel MA, et al. (2016) Solithromycin: a novel fluoro ketolide for the treatment of communityacquired bacterial pneumonia. Drugs 76:1737-1757.

5. Llano-Sotelo B, Dunkle J, Klepacki D, Zhang W, Fernandes P, et al. (2010) Binding and action of CEM-101, a new fluoroketolide antibiotic that inhibits protein synthesis. Antimicrob Agents Chemother 54: 4961-4970.

6. Van Bambeke F (2014) Renaissance of antibiotics against difficult infections: focus on oritavancin and new ketolides and quinolones. Ann Med 46: 512529.

7. Denis A, Bretin F, Fromentin C, Bonnet A, Piltan G et al. (2000) Betaketo-ester chemistry and ketolides. Synthesis and antibacterial activity of 2-halogeno, 2-methyl and 2, 3 enol-ether ketolides. Bioorg Med Chem Lett 10: 2019-2022.

8. Bertrand D, Bertrand S, Neveu E, Fernandes P(2010) Molecular characterization of off-target activities of telithromycin: a potential role for nicotinic acetylcholine receptors. Antimicrob Agents Chemother 54: 53995402.

9. Fernandes $P$, Martens $E$, Bertrand D, Pereira D (2016) The solithromycin journey-it is all in the chemistry. Bioorg Med Chem 24: 6420-6428.

10. Kannan K, Mankin AS (2011) Macrolide antibiotics in the ribosome exittunnel: species-specific binding and action. Ann N Y Acad Sci 1241: 33-47.

11. Rodgers W, Frazier AD, Champney WS (2013) Solithromycin inhibition ofprotein synthesis and ribosome biogenesis in Staphylococcus aureus,Streptococcus pneumoniae, and Haemophilus influenzae. Antimicrob Agents Chemother 57: 1632-1637.

12. Lemaire S, Van Bambeke F, Tulkens PM (2009) Cellular accumulation and pharmacodynamic evaluation of the intracellular activity of CEM-101, a novel fluoroketolide, against Staphylococcus aureus, Listeria monocytogenes, and Legionella pneumophila in humanTHP-1 macrophages. Antimicrob Agents Chemother 53: 3734-3743.

13. Rodvold KA, Gotfried MH, Still JG, Clark K, Fernandes P, et al. (2012) Comparison of plasma, epithelial lining fluid, and alveolar macrophage concentrations of solithromycin (CEM-101) in healthy adult subjects. Antimicrob Agents Chemother 56: 5076-5081.

14. Kobayashi Y, Wada H, Rossios C, Takagi D, Higaki M, et al. (2013) A novel macrolide solithromycin exerts superior anti-inflammatory effect via NFkappaB inhibition. J Pharmacol Exp Ther 345: 76-84.

15. Kobayashi Y, Wada H, Rossios C, Takagi D, Charron C et al. (2013) A novel macrolide/ fluoroketolide, solithromycin (CEM-101), reverses corticosteroid insensitivity via phosphoinositide 3-kinase pathway inhibition. Br J Pharmacol 169: $1024-1034$

16. Still JG, Schranz J, Degenhardt TP, Scott D, Fernandes P, et al. (2011) Pharmacokinetics of solithromycin (CEM-101) after single or multiple oral doses and effects of food on single-dose bioavailability in healthy adult subjects. Antimicrob Agents Chemother 55: 1997-2003.

17. Jamieson BD, Ciric S, Fernandes P (2015) Safety and pharmacokinetics of solithromycin in subjects with hepatic impairment. Antimicrob Agents Chemother 59: 4379-4386

18. Barrera CM, Mykietiuk A, Metev H, Nitu MF, Karimjee N, et al. (2016) Efficacy and safety of oral solithromycin versus oral moxifloxacin for treatment of community-acquired bacterial pneumonia: a global, double-blind, multicentre, randomised, active-controlled, non-inferiority trial(SOLITAIREORAL). Lancet Infect Dis 16: 421-430.

19. File TM Jr, Rewerska B, Vucinić-Mihailović V, Gonong JRV, Das AF, et al. (2016) A randomized, double-blind, multicenter study comparing the efficacy and safety of intravenous-to-oral solithromycin to intravenous-tooral moxifloxacin for treatment of community-acquired bacterial pneumonia. Clin Infect Dis 63: 1007-1016. 